\title{
Clinical complaints: a means of improving quality of care
}

\author{
Pippa Bark, Charles Vincent, Angela Jones, Jane Savory
}

\begin{abstract}
Objectives-To establish the reasons for clinical complaints, complainants' feelings about the original incident, and their motivation in complaining.

Design-Postal questionnaire survey.

Setting-24 hospitals in North West Thames region.

Subjects-1007 complainants who had written to 20 hospitals between 1 January 1992 and 30 June 1993 about a complaint involving a clinical incident.

Main measures-Personal details, the nature of the complaint, the complainant's reaction to the original incident, the quality of the explanation at the time of the incident, the reasons for making a complaint, and what would have prevented the incident.

Results-491 completed questionnaires were received (response rate $49 \%$ ). Complaints arose from serious incidents, generally a clinical problem combined with staff insensitivity and poor communication. Clinical complaints were seldom about a clinical incident alone (54; $11 \%)$; most $(353 ; 72 \%)$ included a clinical component and dissatisfaction with personal treatment of the patient or carer. In all, 242(49\%) complainants reported a need for additional medical treatment, $206(42 \%)$ reported that the patient's condition had worsened as a result of treatment, and $175(36 \%)$ that side effects had been experienced. In $26(5 \%)$ cases the patient had died. Complainants' primary motive was to prevent recurrence of a similar incident. Lack of detailed information and staff attitude were identified as important criticisms.

Conclusions-The emphasis must be on obtaining a better response to complaints at the clinical level by the staff involved in the original incident, not simply on adjusting the complaints procedure. Staff training in responding to distressed and dissatisfied patients is essential, and monitoring complaints must form part of a more general risk management programme.
\end{abstract}

(Quality in Health Care 1994;3:123-132)

\section{Introduction}

The number of complaints received by hospitals has increased fivefold since the patient's charter, and letters of complaint outnumber those of thanks by 50 to one. ${ }^{1}$ The present hospital complaints procedure has received much criticism, ${ }^{2-8}$ being considered cumbersome, insufficiently impartial, and whose explanations are not comprehensive. Most complainants reaching the third stage of independent peer review, an extremely time consuming and expensive procedure, are not satisfied with the outcome, ${ }^{6}$ and criticism from patients does not seem to be welcomed as a way of improving services. ${ }^{2} 3$

Complaints should play a part in improving standards by initiating systematic review of incidents and triggering action to avoid future problems. ${ }^{4}$ In terms of reacting to and handling a complaint, a good system should be "accessible, impartial, speedy, open, and effective." Apologies, when appropriate, should be genuine and not defensive; responsibility should be accepted. ${ }^{10}$ Despite general agreement on the ideal response to complaints actual improvements seem to be few.

Most studies of complaints, including the recent Wilson committee report, ${ }^{5}$ focused on complaints procedures. This is undoubtedly important but fails to address the reasons for the incidents or to consider adequately strategies to avoid recurrence. Many complaints about hospital services seem to arise from deeply upsetting incidents, and administrative efficiency, although certainly welcome, will not meet fully the needs of distressed patients and relatives nor result in improved quality of future care.

Effective handling of complaints should include learning from the situation and preventing recurrence, in line with recent developments in clinical risk management. If clinical staff and complaints officers appreciated the patient's perspective more fully they might be less inclined to react in the defensive ways identified in studies of complaints. Ideally, complaints could be resolved without recourse to formal procedures.

In this study we focused on the original incidents that gave rise to complaints as indicators of what would help to improve the quality of care. We studied the complainants' descriptions of the incidents, their reactions to them, their reasons for making a complaint, and the kind of response they hoped for in making the complaint. By examining the content of the problems we hoped to establish ways of improving the handling of situations to avoid their escalation into formal complaints and to ensure that the information given by the complainant is used productively.
London W2 1NY

20 July 1994 


\begin{abstract}
Methods
DESIGN

A questionnaire was sent to complainants who had written to a hospital in North West Thames region between 1 January 1992 and 30 June 1993. The study was restricted to complaints involving a clinical incident and covered clinical complaints and complaints about communication and attitude. Both closed complaints and complaints in progress were included. Complaints solely concerning non-clinical issues such as waiting times, cleanliness, and car parking were excluded, as were psychiatric complaints and complaints that had proceeded to litigation.
\end{abstract}

\section{PROCEDURE}

Complaints officers at 24 hospitals in the region were invited by telephone to take part in the study. They were asked to identify all complainants who had complained after 1 January 1993 who fell within the design criteria above. Complaints officers excluded a further 33 complainants within the design criteria because they feared that the questionnaire would cause distress. To maintain confidentiality hospitals were asked either to send a list of complainants' addresses to us or to send the questionnaires out directly from the hospital.

A total of 1007 questionnaires was sent out to complainants who had written to one of 20 hospitals. Each questionnaire had a personalised letter signed by two of the authors, explaining the purpose of the study and assuring anonymity and including an instruction sheet, stamped addressed envelope, and contact telephone number. It was made clear that the study could not affect the outcome of the complaint.

As we did not have access to patients' clinical records all information we received was at the complainant's discretion. Maintaining anonymity meant that we could not compare characteristics of respondents and non-respondents.

\section{DESIGN OF QUESTIONNAIRE}

The questionnaire covered nine main subject areas: the patient's personal details; details of the complaint; a description of what happened leading to the complaint; how the complainant felt at the time of the incident(s); the quality of the explanation given at the time of the incident; the clinical effects of the incident(s); the reasons for complaining; what the complainant felt should be done to help dissatisfied patients; and what could be done to prevent a similar situation in future. The questionnaire comprised a combination of 17 closed questions, nine open questions, and 21 statements for which respondents were asked to rate the extent to which they agreed or disagreed on a 5 point rating scale (appendix).

The questionnaire listed nine possible medical reasons for complaining, derived from categories by Mulcahy and Lloyd-Bostock ${ }^{10}$ : problems with admission or discharge, diagnosis, equipment, drugs, tests, treatment, quality or quantity of information given, lack of confidentiality, and staff behaviour or attitude. These were later collaped into three broad categories: clinically orientated problems, communication problems, and a combination of clinical and communication problems.

A distinction was made in this paper between the complainant (the person who wrote the letter of complaint and filled in the questionnaire) and the patient (the person who had needed treatment).

The questionnaire was initially sent out from three hospitals for piloting, and it elicited a $60 \%(18 / 30)$ response rate. It was subsequently modified and condensed into its final form.

\section{Results}

RESPONSE RATE

Of the 24 hospitals invited to participate, four declined: one because of internal staff difficulties; one because the hospital had a patient group with a high number of bereavements, which its chief executive believed made the population unsuitable; and two because the complaints officers believed that the study would be inflammatory.

In all, 559/1007 people responded to the questionnaire, of whom 491 completed the questionnaire and 68, who preferred to explain their circumstances in their own words, wrote letters or telephoned. We analysed only the questionnaire data; the response rate was therefore $49 \%$.

The response rates varied considerably among the hospitals, from $22 \%$ to $67 \%$ (mean $47 \%$, median $48 \%$ ).

\section{PATIENTS' CHARACTERISTICS}

A total of 304(62\%) patients were women; the mean age of all patients was $50 \cdot 3$ (SD 25.2) years. In $241(49 \%)$ cases the complaints referred to inpatient treatment, in $197(40 \%)$ to outpatient treatment and in $36(7 \%)$ to a combination of both; $17(30 \%)$ patients did not specifiy what their complaint referred to.

The mean time of answering the questionnaire since the time of the event was $10 \cdot 3(5 \cdot 31)$ months.

\section{COMPLAINANTS' CHARACTERISTICS}

Of the 491 complainants, $270(55 \%)$ were patients writing to complain about their own treatment; the rest were representatives writing for the patient, typically a family member (196 cases). The most common reasons for writing on someone's half were that the patient was a child (47 patients), too ill or disabled (63), too distressed (18) or dead (26).

\section{HEALTHCARE PROFESSIONAL INVOLVED}

When asked to specify the main person involved in the event(s) the complainants cited doctors (table 1). Twice as many complaints were made about doctors than nurses. On average, complainants said that two main people were involved.

CLASSIFICATION OF ORIGINAL INCIDENT

Table 2 shows the types of problem encountered by the complainants. Many com- 
Table 1 Main healthcare professional involved in complaints

\begin{tabular}{lc}
\hline Staff & No \\
\hline Doctor & 290 \\
Consultant & 96 \\
Senior registrar or registrar & 25 \\
Senior house officer & 23 \\
Unknown & 146 \\
Nurse & 142 \\
Other clinical staff & 26 \\
Administrative staff or management & 68 \\
\hline Total & 526 \\
\hline
\end{tabular}

plaints had several aspects. In most instances (353, 72\%) the complaint stemmed from a combination of clinical and communication problems. Clinical problems alone provoked complaints in 54 instances $(11 \%)$ and communication problems alone in $84(17 \%)$.

COMPLAINANTS' DESCRIPTIONS OF INCIDENTS Complainants' descriptions of the event or events that had led up to the complaint,

An 83 year old man admitted to casualty with a painful leg was told angrily by the doctor that he was wasting his time and was discharged. $\mathrm{He}$ was readmitted later that night by ambulance and operated on for a blocked artery the next morning.

A patient was told that the consultant wanted to try a new surgical technique. The clinical assistant had never heard of the procedure and was instructed on how to do it by the consultant, who left without speaking to the patient at all.

A dying patient was referred to hospital by his GP as his wife was no longer able to cope. The doctor was rude and demanded to know exactly what the patient thought he could do for him as he was not a casualty case. He shouted outside the cubicle, and a nurse intervened. Both the patient and his wife were very distressed. The patient died shortly afterwards.

A pregnant mother advised by her GP to discuss the possibility of a caesarean section with an obstetrician said, "The registrar answered my questions with extreme condescension, criticised my GP in front of me, kept sniggering with the nurse present, and was so patronising I was almost reduced to tears."

Surgeons discussed reversal of colostomy among themselves, ignoring the patient, who was present, and decided to do "whatever is cheapest." A year later the patient still had pain where the drain was inserted and the stomach was red and lumpy.

A child was given analgesics four hours late despite pain after a three hour operation. A used urine bottle was left for two days, and remnants of plaster were left in the bed until the mother cleaned up. The child was discharged early (according to the GP) and the drip needle was left in his arm.

A woman waited for a gynaecology appointment for two and a half hours. She was told to undress in a room with staff coming in and out.

Examinations and tests done were by several different staff. She felt ignored. Her only communication with the consultant was when he said he was doing an internal examination. She had "never experienced such a brutal internal" and asked him to stop. She was told to hurry when dressing as the consultant was busy.

During an operation the anaesthetist dislodged a patient's front tooth while inserting a tube. He did not mention it to the patient or organise dental treatment until the patient asked.

A patient waited 8 hours before a tracheostomy tube was inserted. The staff nurse performing the procedure said she had never done one before, although she had seen one done. Painful insertion that felt like pushing against the patient's windpipe was experienced, with resultant swelling. The patient had difficulty breathing and asked to see a doctor but was told that the doctor was too busy.
Table 2 Types of problem complained about

\begin{tabular}{lr}
\hline Problem & No (\%) \\
\hline Staff behaviour or attitude & $298(61)$ \\
Incomplete or inaccurate information given & $220(45)$ \\
Diagnostic error & $167(34)$ \\
Delayed admission or premature discharge & $142(29)$ \\
Incorrect treatment & $137(28)$ \\
Errors in medication & $84(17)$ \\
Equipment failure & $51(10)$ \\
Problem of investigation & $41(8)$ \\
Confidentiality & $31(6)$ \\
\hline
\end{tabular}

${ }^{\star}$ Multiple responses.

including clinical treatment and the way the patient or carer had been treated personally, usually involved an accumulation of incidents leading up to the formal complaint. Box 1 shows some examples of typical complaints and box 2 an example of the gradual evolution of a complaint.

COMPLAINTS BY SPECIALTY

The main source of complaints were the acute specialties, including general surgery (112,

\section{Wednesday Appointment brought forward due to severe condition and patient admitted for tests \\ Friday Patient examined and informed of flexi-sigmoidoscopy on Monday \\ Saturday Patient given two sachets of sodium picosulphate. Experienced severe stomach pains and diarrhoea throughout the night \\ Sunday Patient fasted, aggravating condition. Diarrhoea again throughout the night \\ Monday am - Ward round. Consultant sympathised. Patient fasted for second day $4.00 \mathrm{pm}$ - Patient anxious and in discomfort. Asked when tests were to be \\ $4.30 \mathrm{pm}$ - A nurse said he was not on the list for Monday. Patient then asked the ward sister who said he had been on list but that they had run out of time. Patient asked to see doctor who agreed but then did not come $9.30 \mathrm{pm}$ - Patient told by a nurse that examination could not be done until the following week at the earliest and that the bed was needed \\ $10.00 \mathrm{pm}$ - Patient discharged confused and unhappy. No proper explanation or apology had been given}

Even at this stage the patient said he "was prepared to let the matter lie" until the following week when he received a phone call from the consultant's secretary to say a cancellation had occurred and asking whether he could attend on the Monday. He agreed but described his reaction to sodium picosulphate and expressed reluctance to repeat the procedure. He was told that they had not known he had been an inpatient and that he had definitely not been on the list for the previous week. In addition, sodium picosulphate was not a necessary part of the procedure 


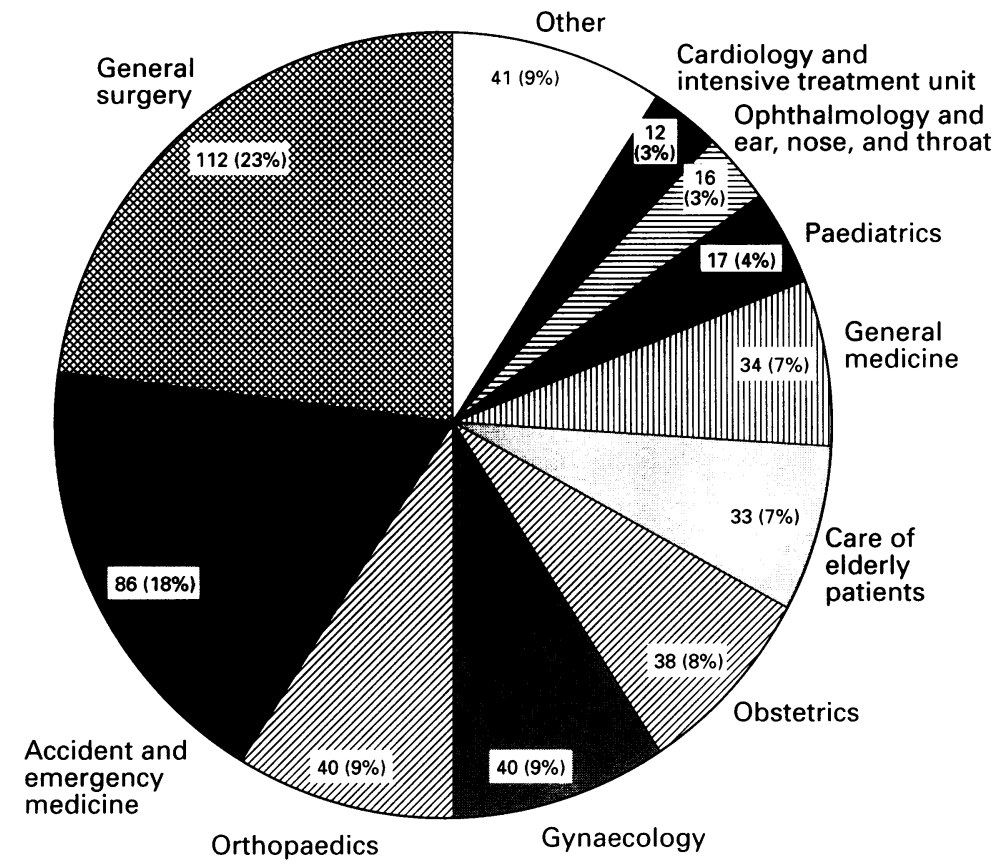

Fig 1 Complaints by specialty $(n=491)$

$24 \%$ ), accident and emergency medicine (86, $18 \%$ ) obstetrics and gynaecology $(78,17 \%)$, and orthopaedics (40, 9\%) (fig 1). As the percentages do not take into account the number of patients in each specialty they do not indicate whether complaints were more or less likely in any one specialty.

Commenting on the clinical and personal aspects of the event that had led to the complaint, most complainants focused on what they thought had caused the problem with treatment, such as failure to take into account the patient's history or lack of supervision for a junior doctor. Responses were coded under 27 categories, the most common of which are described below. Although some variations are partly accounted for by the nature of the clinical conditions in each specialty, some interesting patterns emerged.

Accident and emergency medicine and orthopaedics - The main criticism (40\%, 51/126 complaints) was that staff did not acknowledge the patients' or their carers knowledge of their condition and ignored information they were

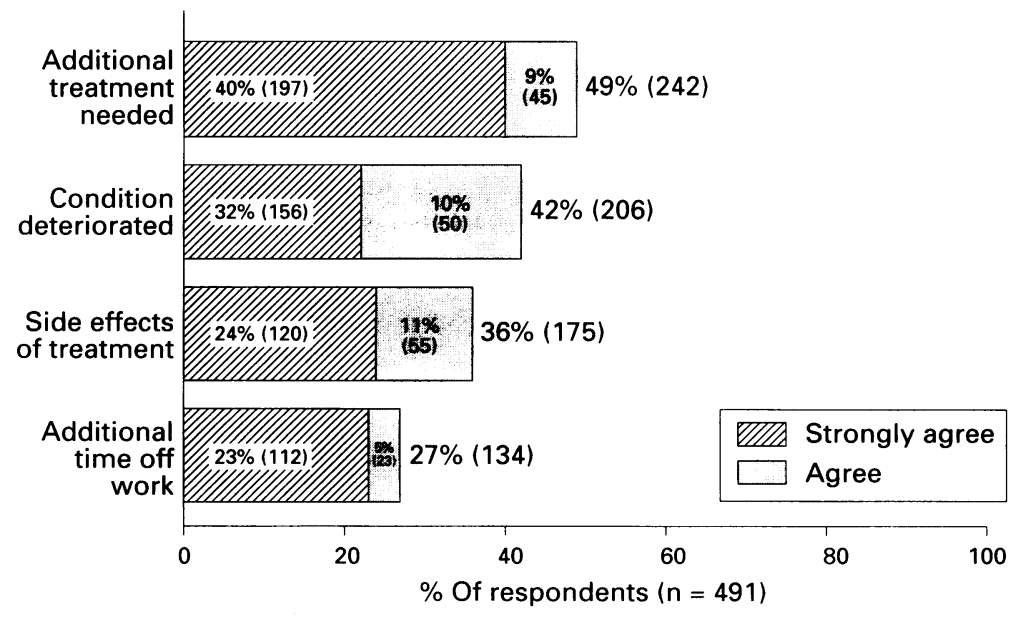

Fig 2 Clinical effects of incident trying to provide. Patients' descriptions of pain were often not believed nor taken seriously, so that appropriate treatment was not instituted. Patients were perceived to be treated with disregard, and rude, condescending, patronising, or off hand attitudes were reported (45\%, 57/126).

General medicine - The principal concern here was an uncaring attitude towards the patients, with a lack of consideration of their feelings or fears and their being treated in an off hand or patronising manner $(68 \%, 23 / 34)$. Patients' knowledge of their medical condition and history was not taken into account $(21 \%$, $7 / 34$ ), and care was perceived as neglectful in several instances $(24 \%, 8 / 34)$.

Paediatrics and care of elderly patients - The most common complaint was that paediatric staff did not appreciate that children need to be approached differently from adults $(35 \%, 6 / 17)$ - for example, failure to respond to a small child in pain or using inappropriate language to talk to a child. Parents were frequently upset by being kept away from their child and then finding that he or she had been left alone for long periods $(29 \%, 5 / 17)$. Elderly patients and their carers were often not credited with any knowledge of the condition $(42 \%, 14 / 33)$ and the particular care needs of an individual person were not taken into account $(24 \%, 8 / 33)$. Lack of respect for the patient was the most frequent complaint $(67 \%, 20 / 33)$ : patients felt humiliated or degraded by their treatment and were treated in a condescending or patronising fashion; some were believed to have been neglected $(27 \%, 9 / 33)$.

General surgery - The main issues in surgery were an impersonal approach $(21 \%, 24 / 112)$ and a lack of discussion with the patient. The patient's history and condition were not taken into account or believed $(26 \%, 29 / 11)$, and patients were not given sufficient information about what was happening $(26 \%, 29 / 112)$. Also reported was an uncaring and off hand attitude or being treated with contempt by a surgeon $(38 \%, 42 / 112)$.

Obstetrics and gynaecology - Being treated without respect or with contempt were the most common complaints $(62 \%, 48 / 78)$ in these specialties. Dehumanisation was often mentioned, and gynaecological patients felt humiliated by their treatment and the attitudes of staff. Many were distressed by the impersonal approach $(28 \%, 22 / 78)$. Patients' knowledge of their history or condition was not adequately considered $(44 \%, 34 / 78)$ and $33 \%$ of complainants $(26 / 78)$ thought that inconsistent or inappropriate treatment decisions had been made.

EFFECTS OF THE INCIDENT

Patients considered that serious clinical effects often arose from original mistreatment or misdiagnosis, leading to a delay in obtaining correct treatment: their condition deteriorated $(206,42 \%)$, additional clinical treatment was needed $(242,49 \%)$, side effects were experienced $(175,36 \%)$ and a quarter of patients needed additional time off work (fig 2). 


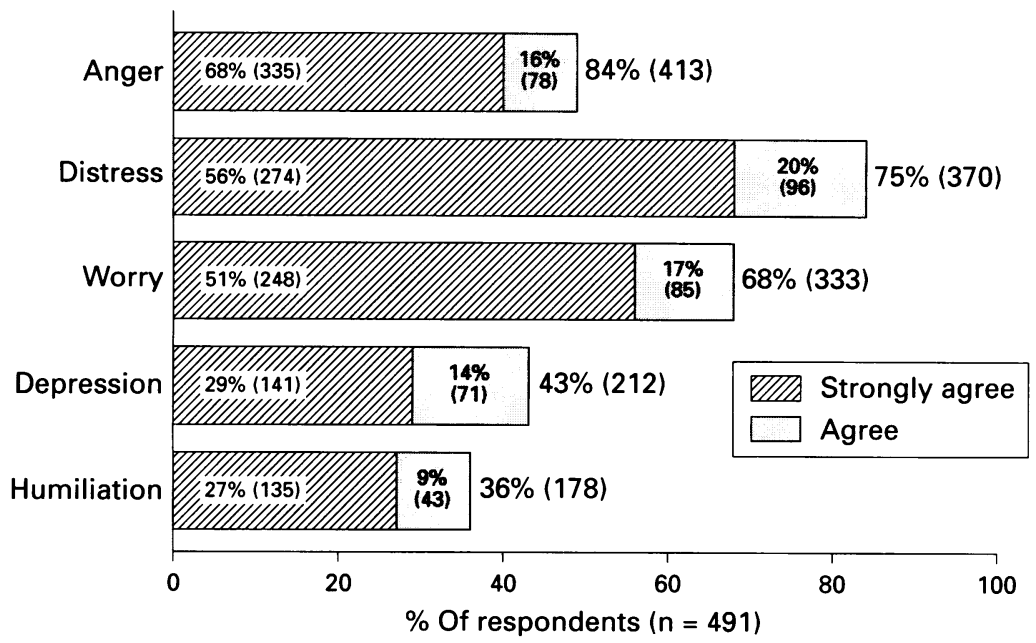

Fig 3 Emotional effects of incident

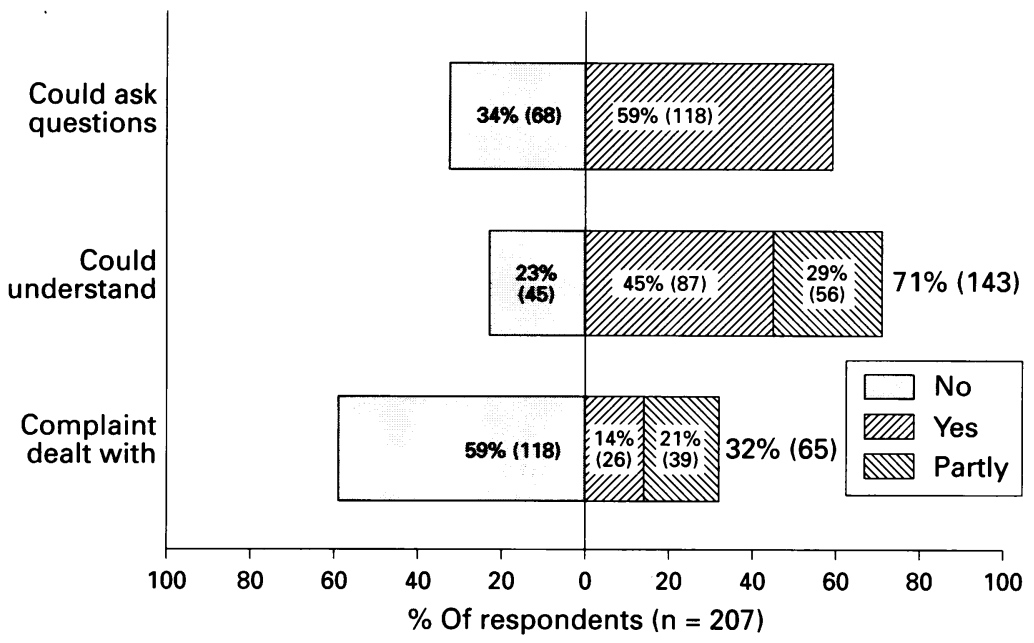

Fig 4 Quality of information at time of incident

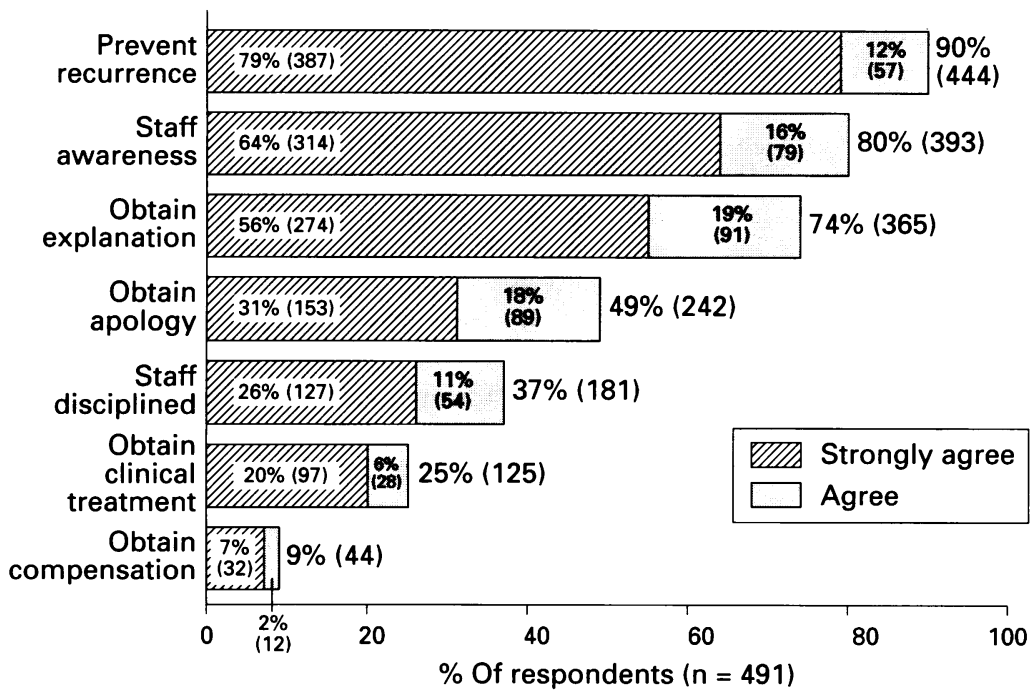

Fig 5 Reasons given for complaining

Emotional effects - Complainants were often critical of staff behaviour. They agreed or strongly agreed with the questionnaire statements that their feelings had been ignored $(301,61 \%)$, staff were unsympathetic (264, $54 \%$ ) or they were treated as if they were stupid $(209,43 \%)$. In total, 353(72\%) reported experiencing emotional pain and suffering as a result of the incident, describing strong feelings of anger, distress, worry, and depression, and over a third $(36 \%, 178)$ reported humiliation (fig 3 ).

\section{QUALITY OF EXPLANATION AT TIME OF} INCIDENT

Complainants were asked about the quality of the explanation they (or the patient) had received at the time of the event or events. Only $201(41 \%)$ said they had been given an explanation at this time, of whom, 68(34\%) had not had the opportunity to ask questions, $118(59 \%)$ said that the explanation had not dealt with the issue, and only $87(43 \%)$ reported that they had fully understood what had been said to them (fig 4).

REASONS FOR FORMAL COMPLAINT

All complainants reported a combination of reasons for their written complaints. In all, $444(90 \%)$ wanted to prevent a similar incident to avoid others having to go through a similar experience. They also wanted evidence that preventive or curative action had been taken. People wanted staff to be aware of what had happened and the effect it had had on the patient. Some complainants, in seeking an explanation, simply wanted more information about their condition or treatment; others, when something had gone wrong, required a detailed account of what had happened and an explanation. A quarter (125) wrote to draw attention to their medical condition as a way of getting further clinical treatment. Only a minority of complainants wanted compensation, usually for small losses incurred or to cover costs such as dental bills for damaged teeth in anaesthetic mishaps.

EXPERIENCE OF MAKING A COMPLAINT

For many patients and relatives the complaints process compounded their dissatisfaction or distress, and only seven (1\%) said that the response was very good or satisfactory, with no criticisms. The attitudes that had caused distress and dissatisfaction during treatment were again encountered when they complained; $91(19 \%)$ replied that there was nothing they liked about the response at all. Patients seldom believed that their views had been taken seriously and only $40(8 \%)$ stated explicitly that action had been taken to prevent the same issue arising again. The main criticism concerned a lack of detailed, open information: comments were that the complainant was fobbed off with excuses (166, $34 \%$ ), the reply was vague or inaccurate (100, $20 \%$ ), and an impersonal standardised letter had been sent $(28,6 \%)$. Excuses or vagueness were interpreted as staff closing ranks to cover up, and the complainants felt they had been lied to. Other major criticisms concerned lack of effective action or no forthcoming solution $(99,20 \%)$. The way the complainant was dealt with was considered arrogant or patronising, with an indication of the complainant making "a fuss over nothing" $(51,10 \%)$.

When asked what they had liked 178 complainants did not state any element. 
However, most valued at least one element of the handling of the complaint: the speed of the initial reply $(61,12 \%)$, prompt dealing of the matter $(25,5 \%)$ or receipt of a reply at all $(70,14 \%)$. Responses were valued for being conciliatory or for offering an apology $(49,10 \%)$; for being honest; and, in a few cases, for responsibility having been accepted for what had gone wrong $(26,5 \%)$ and for a comprehensive explanation $(62,13 \%)$. It was appreciated when the key person in the original incident was involved in the response $(31,6 \%)$. The tone of the responses was clearly important, complainants appreciating the reply being professional, courteous, polite, sympathetic, or concerned $(78,16 \%)$.

HELPING PEOPLE DISSATISFIED WITH TREATMENT

Three hundred and seventy four complainants gave, on average, 1.3 comments for helping people dissatisfied with their medical treatment (total 499 comments), and these were coded in eight main categories as reported below; 54 complainants, thought that nothing could be done at this stage, $14(3 \%)$ because they considered that an adequate system already existed and $40(8 \%)$ because it was too late.

The most frequent recommendation (126, $26 \%$ complainants) was to use complaints constructively to learn about quality of care and to aim at improving the service offered for example, by having a routine satisfaction survey on discharge, encouraging patient comments and recommendations, and providing the opportunity for anonymous feedback about services. An advisory service for dissatisfied patients was requested by $111(23 \%)$ complainants, with the need to simplify the complaints procedure and for greater publicity about available help. Face to face contact was considered preferable to correspondence. Seventy seven (16\%) complainants asked for personal resolution of the problem in the form of an apology or action to prevent recurrence of the event and 77 asked for a comprehensive explanation and a full account of the facts, sometimes including an expert opinion. The remaining comments concerned accepting responsibility for what had happened, considering the patient's perspective, and disciplining the people involved $(36,7 \%)$.

PREVENTIVE ACTION

In total, 466 complainants gave, on average, 1.6 suggestions for preventing a similar situation (total 754 comments), which were coded in nine main categories, the key features of which are reported below.

The key issue revolved around staff training and selection $(162,33 \%)$. In service training was recommended, particularly in relation to communication, involving learning to deal more effectively with specific groups of patients, such as distressed or bereaved people, and very young or elderly patients. In some cases complainants thought the member of staff was unsuitable for their post and recommended a review of staff selection procedures. Increased involvement of senior staff in care was requested in 50 cases $(10 \%)$. Complainants recommended improvements in information exchange, record keeping, and staff manner to improve quality of care and requested more information and relevant explanation by staff throughout the care of the patient (including the complaints procedure) and attention and response to information that patients and carers have to provide $(139,28 \%)$. A related point was the use of the patient's medical history; complainants criticised inaccuracies in the clinical notes and recommended improvements in the recording of notes and also that staff take greater account of the patient's or carer's own knowledge of the medical history $(41,8 \%)$. A hundred $(20 \%)$ complainants requested greater respect for patients and their treatment as individuals; rude, condescending, and patronising attitudes were unacceptable.

Limited resources in the NHS was a common theme among responses (164, 33\%), complainants emphasising the need for more beds, increased staffing, more equipment, resources to develop new procedures, and the need to spend more time with patients (26, $5 \%$ ). Suggestions for a review of disciplinary procedures $(24,5 \%)$ and greater accountability $(23,5 \%)$ were also noted.

\section{Discussion}

Complainants want changes to be made as a result of their experiences. The results from this study highlighted several key issues that must be recognised if we are to improve quality of care and avoid similar future complaints. Firstly, most complaints stemmed from incidents regarded as serious by complainants that had led to significant clinical consequences and distress. In many instances a deterioration in clinical condition had led to additional treatment and longer stays in hospital. Secondly, clinical complaints are seldom about an error of clinical judgement alone but are often about staff insensitivity and poor communication. Thirdly, the way the complaint was handled compounded the difficulties and intensified the dissatisfaction or distress that had led to the complaint.

Bearing in mind the high level of criticism reported in this study, it is important to consider how representative the sample population is. In selecting complainants the complaints officers and the four hospitals who chose not to take part slightly extended the exclusion criteria. Three groups of complainants may be under-represented: those who are bereaved, those still extremely dissatisfied, and those with more extreme clinical effects of their treatment, arising from the hospitals' own decision to exclude certain bereaved relatives or complainants who might have been further upset, including potential litigants. In addition, conversations with complaints officers suggested that bereaved relatives may prefer a discussion rather than a written response and may therefore be under- 
represented in a sample of written complaints. The numbers of exclusions were considered small in relation to the overall sample size and we do not believe that the overall conclusions have been affected.

The wide variation in response rates among the hospitals was surprising. However, maintaining confidentiality meant that the characteristics of respondents and non-respondents would not be compared, nor could the reasons for not responding be examined. Out of date records of current addresses and high proportions of non-English speakers may well have been contributory factors.

In terms of a self selection bias, the 68 descriptions of complaints we received by letter, volunteered case files, and telephone calls seemed similar in character to those in the completed questionnaires. However, the remaining 448 non-respondents may have included a higher level of complainants who thought that their complaint had been satisfactorily resolved and were therefore less motivated to participate. If this is so the high level of agreement in responses received is still unlikely to be appreciably affected.

Complainants' suggestions for preventing recurrences of such situations is in line with current thinking on risk management. The information received from complainants must be used more effectively and fed back into the process of monitoring and improving the standards of care. Ensuring preventive action has been taken and inviting complainants to visit and observe would do much to repair their lost confidence, however long after the event changes are instituted, and would avoid the lengthy and frustrating process of a protracted complaint.

Better communication is certainly needed, both during treatment and in handling a complaint. The most frequent precursors to a problem with treatment seemed to be insufficient notice of patients' knowledge of their condition and history and a perceived uncaring or patronising manner among the staff. Complainants repeatedly emphasised the need for increased patient involvement in making decisions and being kept informed about what was happening. Better communication in these circumstances means not only a willingness to listen and provide information but also an ability to appreciate the emotions experienced by distressed or injured patients.

As recommended by the complainants, specific training for staff in coping with dissatisfied, angry, or distressed patients and relatives is essential. We need to recognise that empathy, sympathy, and the ability to admit to mistakes are attributes that doctors need to acquire and maintain. Formal support or counselling should also be considered for both staff and patients involved in disturbing or injurious incidents. Although the Wilson committee $^{5}$ recommended that training in handling complaints should be available "to all NHS practitioners and staff who are, or are likely to be, in contact with patients," the financial resources are not available. We need to focus initially on staff dealing with the complainants - that is, the clinical staff and the complaints officers. In the long term, one solution may be to redefine the role of complaints officers to take on a training and support function for staff in addition to their present investigative and conciliatory roles.

Anecdotal evidence suggests that satisfying patients' and complainants' needs may be hampered by fear of potential litigation. Complainants requested honest explanations when something went wrong and an apology and an admission of responsibility where appropriate. If litigation is a real fear a clear policy must be agreed between managers and clinical staff that explanations to patients are justifiable on clinical and humanitarian grounds, even at the risk of ensuing litigation. When something has gone wrong taking an active stance in communciating with patients and carers so that early restorative action can be initiated before they complain can only be beneficial. As many patients sue partly because they want an explanation, ${ }^{11}{ }^{12}$ this is probably a sound financial policy as well as a humane one. This basic element should be a cornerstone of a wider, formal risk management programme.

If complaints are to be used to improve the quality of care, and if patients are to believe that critical incidents have some impact, there must be a mechanism for using positively the information gathered from critical incidents and complaints. Although complaints databases are becoming increasingly common, we are still far from having efficient ways of analysing information so that it can be acted on clinically. In practice this will entail introducing a formal risk management system to allow routine reviews of all serious complaints and untoward incidents.

Ultimately, the kind of changes in clinical procedures requested by complainants can come only from clinicians. If this is to happen the staff involved in the original incident must be closely involved in resolving a complaint and the manager who coordinates the formal response to a complaint must have direct influence on clinical staff. Complaints should be dealt with by a senior member of staff with influence in the organisation, reporting to the chief executive and clinical director.

The difficulties we have with complaints goes far beyond the complaints procedure. The present inability to address problems as they occur exacerbates already difficult situations. Our attitudes to complainants and their complaints must change if our response is to be effective in improving quality of care.

We thank Laura Olivieri for coding the data, Alison Davies for help with administration of the study, and the hospital corticular, we thank all the complainants who wrote and discussed their experiences with us.

1 Davies P. Lazy Monday afternoon. Health Service fournal 1993;25 Feb:20.

2 Association of Community Health Councils in England and Wales. NHS complaints procedures - a review. ACHCEW, 1990

3 Donaldson LJ, Cavanagh J. Clinical Complaints and their handling: a time for change? Quality in Health Care 1992;1:21-5. 
4 National Association of Health Authorities and Trusts. Complaints do matter. A consultative paper on future NHS complaints arrangements. London: NAHAT, 1993.

5 Wilson Committee. Being heard. The report of a review committee on NHS complaints procedures. London: Department of Health, 1994

6 Kaye C, MacManus T. Understanding complaints. Health Service fournal. 1990;23 Aug:1254-5.

7 Longley D. Out of order. Health Service fournal 1992;26 Nov:22-4.
8 Stacey M. Green shoots. Health Service fournal 1993;21 Jan:20-2.

9 Winkler F. Complaints by patients. BMf 1993;306:472-3.

10 Mulcahy L, Lloyd-Bostock S. Complaining - what's the use? Quality and Regulation in Health Care 1990;51-68.

11 Simanowitz A. Standards, attitudes and accountability in the medical profession. Lancet 1985;ii:546.

12 Simanowitz A, Accountability. In: Vincent CA, Ennis $M$ Audley RJ, eds. Medical accidents. Oxford: Oxford University Press, 1993;209-21.

\section{Appendix}

\section{North West Thames Regional Health Authority Questionnaire on reasons for complaining}

\begin{tabular}{|l|}
\hline \multicolumn{1}{|c|}{ About the person involved } \\
\hline Age of patient: \\
Male/female \\
Was the patient an inpatient [ ] or an outpatient [ ]? \\
Which ward or department? (for example general surgery, \\
gynaecology, paediatrics, accident and emergency) \\
Which hospital? \\
Is treatment complete? Yes/No \\
Date you are filling in this form:
\end{tabular}

\section{About the complaint}

1. When did the event or set of circumstances happen?

2. Were you complaining for:
Yourself
Go to question 4
A relative
Other. Please specify

3. Please say why the patient did not complain himself or herself

\section{Circumstances that led you to complain}

4. Please give a brief description of what you were unhappy about

5. Which of the following best describes what went wrong? (Please tick all that apply)

A lack of confidentiality

A problem with admission/discharge

A problem with diagnosis

A problem with equipment

A problem with information given

A problem with medication

A problem with staff behaviour or attitude

A problem with tests

A problem with treatment

Other. Please specify

6. Who was the main person involved? (Please tick one)

Hospital doctor

Nurse

Other. Please specify

7. Do you know the grade of the person involved? (consultant, registrar, senior house officer, etc) 


\section{Way you were treated as a person}

8. How did the medical staff treat you? (Please rate all of the statements below according to how you felt)

I was treated as if I was stupid

Strongly disagree Disagree Neutral Agree Strongly agree

My feelings were ignored

Staff were rude

Staff were unsympathetic

\begin{tabular}{lllll}
1 & 2 & 3 & 4 & 5 \\
1 & 2 & 3 & 4 & 5 \\
1 & 2 & 3 & 4 & 5 \\
1 & 2 & 3 & 4 & 5 \\
\hline
\end{tabular}

\section{How you felt after the incident}

9. How did you feel after the incident(s)? (Please rate all of the statements below according to how you felt)

I was angry

I was depressed

I was distressed

I was humiliated

I was worried Strongly disagree Disagree Neutral Agree Strongly agree

I was worried

\begin{tabular}{ccccc} 
Strongly disagree & Disagree & Neutral & Agree & Strongly agree \\
1 & 2 & 3 & 4 & 5 \\
1 & 2 & 3 & 4 & 5 \\
1 & 2 & 3 & 4 & 5 \\
1 & 2 & 3 & 4 & 5 \\
1 & 2 & 3 & 4 & 5 \\
\hline
\end{tabular}

\section{Explanation you were given at time of treatment}

10. At the time of the incident(s), did the medical staff give you an explanation?

$$
\begin{array}{ll}
\text { Yes } & \square \quad \text { Go to question } 11 \\
\text { No } & \square \quad \text { Go to question } 12
\end{array}
$$

11. How good did you think the explanation was? (Please ring one response for each statement)

\begin{tabular}{|c|c|c|c|c|c|}
\hline \multicolumn{6}{|c|}{ The effects of the incident(s) } \\
\hline \multicolumn{6}{|c|}{$\begin{array}{l}\text { 12. What was the effect of what happened? (Please rate all of the statements below according to your } \\
\text { circumstances) }\end{array}$} \\
\hline & Strongly disagree & Disagree & Neutral & Agree & Strongly agree \\
\hline Additional treatment was needed & 1 & 2 & 3 & 4 & 5 \\
\hline Condition worsened & 1 & 2 & 3 & 4 & 5 \\
\hline Emotional pain and suffering & 1 & 2 & 3 & 4 & 5 \\
\hline Extra time off work & 1 & 2 & 3 & 4 & 5 \\
\hline Side effects & 1 & 2 & 3 & 4 & 5 \\
\hline \multicolumn{6}{|c|}{ Your views about treatment } \\
\hline \multicolumn{6}{|c|}{$\begin{array}{l}\text { 13. What criticisms do you have of the way you, your relative, or friend was treated medically? } \\
\text { 14. What criticisms do you have of the way you, your relative, or friend was treated as a person? } \\
\text { 15. Overall what aspect upset you most? }\end{array}$} \\
\hline
\end{tabular}

$\begin{array}{llll}\text { I had the chance to ask questions } & \text { Yes } & \text { No } & \\ \text { I could understand the explanation } & \text { Yes } & \text { No } & \text { Partly } \\ \text { The explanation dealt with my complaint } & \text { Yes } & \text { No } & \text { Partly }\end{array}$

\section{Your reasons for making a complaint}

16. What did you hope for when making the complaint? (Please rate all of the statements below according to how you felt)

I did not want it to happen to

Strongly disagree Disagree Neutral Agree Strongly agree anyone else

I wanted an apology

I wanted an explanation

I wanted clinical treatment

I wanted financial compensation

I wanted staff disciplined

$\begin{array}{lllll}1 & 2 & 3 & 4 & 5 \\ 1 & 2 & 3 & 4 & 5 \\ 1 & 2 & 3 & 4 & 5 \\ 1 & 2 & 3 & 4 & 5 \\ 1 & 2 & 3 & 4 & 5 \\ 1 & 2 & 3 & 4 & 5 \\ 1 & 2 & 3 & 4 & 5\end{array}$




\section{Response to your complaint}

17. Who has replied to your complaint?

No one

Go to question 20

Complaints officer

Doctor

Someone else. Please specify

18. What did you like about the response?

19. What did you not like about the response?

\section{What needs to be changed}

20. What can be done to prevent similar things happening again?

21. What can be done to help people dissatisfied with their treatment?

Please add any further comments you think are relevant overleaf. 